\title{
Noroeste do Paraná: a dinâmica da paisagem rural nas zonas de
} contato arenito-basalto

\section{Northwestern Paraná: the dynamics of rural landscapes at the contact zone af arenites and basalt}

Maria Teresa de Nóbrega

Elpídio Serra

Universidade Estadual de Maringá

\begin{abstract}
Resumo: O Noroeste do Paraná teve sua colonização sustentada na pequena propriedade e nas lavouras cafeeiras, com o homem morando na zona rural e explorando diretamente a terra. Nos anos 1970, o café entrou em crise e cedeu espaço para as lavouras mecanizadas nos solos derivados do basalto e para as pastagens nos solos originados do arenito da Formação Caiuá. Mais recentemente, essas formas de cultivo passam a disputar espaço com as lavouras de cana. As transformações são dinâmicas em toda a mesorregião, mas são mais intensas nas zonas de contato arenito-basalto, sendo este o enfoque do presente trabalho.

Palavras-chave: Noroeste do Paraná. Sistema rural. Paisagem. Zona de contato. Modelos agrícolas.
\end{abstract}

\begin{abstract}
The Northwest of Paraná had sustained colonization in the small property and the coffee plantations, with the man living in the countryside and exploring the land directly. In the 1970s coffee was in crisis and gave way to mechanized farming in soils derived from basalt and grassland soils originated from the sandstone formation Caiuá. More recently, these forms of culture begin to jostle for space with the sugar cane. The changes are dynamic throughout the middle region, but are more intense in areas of sandstone-basalt contact, which is the focus of this work.
\end{abstract}

Keywords: Northwest Paraná. Rural system. Landscape. Contact zone. Agricultural mo-dels. 


\section{INTRODUÇÃO}

Considerando como áreas de estudo para o desenvolvimento do presente traba1 lho ${ }^{1}$ duas zonas de contato arenito-basalto no Noroeste do Paraná, uma compreendida pela extensão total dos municípios de Floraí e São Carlos do Ivaí, no médio vale do rio Ivaí e outra compreendida pela extensão total dos municípios de Francisco Alves e Alto Piquirí, no baixo vale do rio Piquirí, pretende-se neste trabalho, em linhas gerais, analisar a evolução da paisagem e, ao mesmo tempo, do sistema rural das respectivas áreas e, em escala ampliada, da mesorregião Noroeste, onde as áreas de referência estão inseridas. Duas vertentes serão consideradas, tanto em relação ao espaço menor (os municípios localizados nas zonas de contato) quanto em relação ao espaço maior (a mesorregião Noroeste): a que caracterizou a fase da ocupação pioneira e a que caracteriza a fase atual, que incorpora as recentes transformações ocorridas no espaço agrário, com destaque para o avanço das lavouras de cana-de-açúcar. Considerando a primeira vertente, serão resgatadas situações que marcaram o processo histórico regional, valorizando particularmente as condições de acesso à terra e seu uso econômico para fins agrícolas; considerando a segunda vertente, serão analisadas as condições atuais de uso do solo, valorizando as conseqüências sociais e econômicas geradas pela crise do café e sua substituição por lavouras mecanizadas e pastagens plantadas e, mais recentemente, pela introdução das lavouras de cana-de-açúcar.

Em linhas gerais, o estudo vai estar centrado nas modificações do sistema rural e nos reflexos produzidos na paisagem nas escalas local e regional. A propósito, entende-se por sistema o conjunto de partes coordenadas entre si e que levam a um re- sultado concreto, configurado na paisagem construída pela ação humana; entende-se por rural o que se refere ao campo, o que é próprio do campo; entende-se por paisagem o produto final resultante da interação entre o homem e a superfície terrestre. A utilização dos termos "sistema", "paisagem" e "rural" no contexto do Noroeste do Paraná permite entender, por exemplo, que o processo histórico que caracterizou a ocupação regional foi produto da sintonia entre diversos fatores constituintes de um sistema, destacando-se as características físicas do solo e sua aptidão para determinadas formas de uso, a repartição da terra e sua apropriação jurídica, a fixação do homem no campo e a própria origem dos primeiros moradores. Da mesma forma, evoluindo para a atualidade, a utilização dos termos indica as novas condições do uso do solo agrícola se impondo às limitações naturais impostas pela natureza e atendendo às demandas dos mercados nacionais e internacionais, o esvaziamento social do campo, a concentração fundiária, a incorporação de tecnologias e outras marcas produzidas pelos sistemas agrícolas que sucederam ao modelo tradicional na região.

O estudo foi viabilizado a partir do projeto de pesquisa intitulado "O sistema rural e a paisagem nas zonas de contato arenito/basalto na região Noroeste do Paraná" financiado pela Fundação Araucária. Como procedimento metodológico, além de revisão bibliográfica, foram levantados dados dos recenseamentos demográficos e agropecuários do IBGE e dados produzidos pela SEAB - Secretaria de Estado da Agricultura e do Abastecimento, pelo DERAL - Departamento de Economia Rural, pelo IPARDES - Instituto Paranaense de Desenvolvimento Econômico e Social, e pela EMATER - Empresa de Assistência e Extensão Rural. Levantamentos de campo e entrevistas com técnicos e produtores 
rurais subsidiaram o trabalho, com dados e informações relacionados ao cotidiano da agricultura regional e de seus atores sociais.

\section{COLONIZAÇÃO E DESENVOLVIMENTO RURAL}

O Noroeste do Paraná, mesorregião integrada à região Norte do Paraná, teve seu processo de ocupação humana e repartição da terra completado nos anos 1960, em sua maior parte com a participação direta de empresas colonizadoras particulares. As empresas privadas é que foram as maiores responsáveis pela organização do espaço e pela construção da paisagem na fase da ocupação pioneira, mantendo, para isso, um sistema de parceria com o Estado. No sistema de parceria as empresas, ligadas a grupos econômicos atrelados ao setor imobiliário, recebiam do Estado a baixo custo áreas virgens e de grande potencial no mercado, dotavam tais áreas da infra-estrutura necessária para facilitar a ocupação humana, e estabeleciam o planejamento na repartição das terras, suprindo, assim, o espaço com os mecanismos básicos que ao mesmo tempo garantiriam o sucesso da colonização e viabilizariam o desenvolvimento rural. O sucesso da colonização era garantia de sucesso do desenvolvimento, que se daria na medida em que os lotes rurais comercializados e explorados economicamente iriam incrementar a circulação de mercadorias, principalmente matérias primas agrícolas transformando-se, conseqüentemente, em geradores de riquezas.

Com algumas diferenças por conta do período de ocupação, da origem dos compradores de terra, da empresa responsável pela colonização e de características físicas locais, pode-se afirmar que o Noroeste paranaense, em toda a sua dimensão geográfica, teve o mesmo processo de ocupação humana, de repartição das terras e de uso econômico, seguindo sempre as tendências e o comportamento do mercado, tanto imobiliário quanto do setor agrícola. $\mathrm{O}$ café, em praticamente toda a mesorregião, foi o produto agrícola que capitaneou economicamente a colonização, sendo o motivo principal pela procura e conseqüente venda dos lotes rurais. Apesar da crise que enfrentou nos anos 1960, logo que se esgotou a onda colonizadora, o café se manteve ainda como motor da economia em todos os tipos de solo até meados dos anos 1970, quando fortes geadas aplicaram o que foi considerado o golpe de misericórdia na atividade. Destruídas as lavouras, o espaço liberado pelo café, num primeiro momento foi ocupado pelas lavouras mecanizadas de soja, trigo e milho, nas zonas de domínio dos solos derivados do basalto, conhecidos como terra roxa, ficando as zonas de domínio do arenito da Formação Caiuá para o desenvolvimento de lavouras de algodão, seguidas de pastagens tendo em vista a pecuária de corte. Nas áreas caracterizadas como frentes de contato arenito-basalto, em que predominam "solos mistos", ora com maior teor de argila, ora com maior teor de areia, tal comportamento definido de exploração agrícola não é seguido à risca. As características pedológicas próprias das áreas de contato fazem dos "solos mistos" espaços de produção que tanto servem ao modelo utilizado nas faixas de domínio do arenito, quanto ao modelo de lavouras mecanizadas utilizado naquelas do basalto. Tal versatilidade, a propósito, é que torna as zonas de contato atraentes para o desenvolvimento de estudos, principalmente na área da Geografia.

Respeitando as especificidades físicas de cada área, a nova forma de uso do solo define um novo perfil para a economia agrícola e, ao mesmo tempo, desenha uma nova paisagem para a região. No que se refere ao perfil agrícola, onde quase tudo era 
café (exceções ficavam por conta das áreas de fundo de vale, onde o risco de geadas era maior), ficou sendo lavoura mecanizada nos solos oriundos de rochas basálticas e algodão seguido de pastagem no arenito. No que se refere à paisagem, toda a estrutura construída no lote pelo proprietário em função das lavouras de café, constituída de moradias para a própria família e para as famílias dos empregados, o terreiro e a tulha para secagem e o armazenamento do café, e ainda o paiol, o galinheiro, o pomar e muitas outras benfeitorias que garantiam a fixação do homem no campo e a sua subsistência, teve que desaparecer, dando lugar a uma nova paisagem, mais homogênea do que a anterior. Na nova paisagem, o espaço do café e o espaço das construções e das lavouras de subsistência, bastante diversificadas, foram ocupados pelas lavouras especializadas para atender à demanda do mercado. Desapareceu o habitat do morador, proprietário ou empregado, que migrou para as cidades, esvaziando o campo e inchando as áreas urbanas. Desapareceu, também, a base do modelo colonizador voltado às pequenas propriedades, que se adaptaram ao café, mas que não serviu ao novo padrão produtivo, dependente de grandes áreas para o cultivo.

As modificações produzidas no espaço rural pelo novo modelo agrícola foram radicais, mas não definitivas: o perfil agrícola e a paisagem sofreriam ainda novas transformações, mais uma vez atendendo aos apelos do mercado, entre o final dos anos 1980 e o início dos anos 1990. Nesse período, atraídas por estímulos governamentais na forma de isenção de impostos e créditos subsidiados, usinas de açúcar e álcool são implantadas na região, o que induz ao avanço e domínio de lavouras de cana, principalmente nas áreas de ocorrência do arenito. O mais recente padrão produtivo define alterações na paisagem não concluídas em função do modelo anterior e cria outras: a concentração da estrutura fundiária, iniciada com as pastagens e as lavouras de soja, milho e trigo é acelerada; da mesma forma é acelerado o esvaziamento do campo; o proprietário rural se fixa em definitivo nos espaços urbanos e perde sua identidade de agricultor ao deixar de explorar a terra, que passa a ser explorada pela usina sob a forma de arrendamento.

De maneira geral, a cana vem ocupando o lugar das pastagens na área de ocorrência do arenito e disputa espaços com as lavouras mecanizadas (soja, principalmente) nos solos argilosos da área do basalto e nas zonas de contato arenito-basalto. Nesses tipos de solo, o avanço da cana ou a resistência da soja fica na dependência do comportamento ou do humor do mercado de commodities agrícolas. Quando o preço é favorável para a soja, esta domina; quando a cana é que tem o melhor preço, o domínio é dos canaviais e, consequentemente, se amplia o estoque de terras em poder das usinas.

\section{A CRISE DO CAFÉ E O NOVO MODELO AGRÍCOLA}

O modelo de colonização adotado no Noroeste do Paraná pelas empresas loteadoras contemplou, de maneira geral, a pequena propriedade tendo o agricultorproprietário morando no campo e explorando diretamente a terra, contando com a participação da mão-de-obra familiar não remunerada e alguns poucos empregados fixos, igualmente morando na propriedade. A principal empresa colonizadora a atuar na região, a CTNP - Companhia de Terras Norte do Paraná, posteriormente designada CMNP - Companhia Melhoramentos Norte do Paraná, responsável por uma área correspondente a 1.300.000 hectares, explica como foi a demarcação 
dos lotes rurais e sua forma de uso:

\begin{abstract}
A zona rural colonizada pela Companhia foi dividida em pequenos lotes, de área variável, demarcados de tal maneira a incluírem todos eles uma parte de baixada e uma de espigão. Contam, ainda, com água corrente e acesso por estrada de rodagem. Na parte da baixada o colono geralmente constrói sua casa, planta um pomar e uma horta, cerca um pasto, enfim, produz o necessário para a subsistência. Nos trechos mais elevados, menos atingidos pelo frio, estende seu cafezal, que constitui a sua principal fonte de renda. (CMNP, 1975, p.114).
\end{abstract}

Embora tendo se iniciado na região Norte na década de 1930, só nos anos 1940 é que a marcha colonizadora atinge a área denominada Norte Novíssimo Paranaense que coincide, em toda a sua dimensão e limites, com a mesorregião Noroeste. As lavouras de café se constituem na principal base de sustentação econômica do espaço colonizado e, ao mesmo tempo, o principal motivo que vai justificar o rápido e intenso processo de comercialização dos lotes rurais. As transações imobiliárias eram impulsionadas pelas perspectivas favoráveis do café no mercado externo, que funcionavam como garantia de que o lote negociado era lote pago, graças aos lucros gerados pela atividade cafeeira.

A sintonia entre os negócios imobiliários, o uso da terra e a fixação do homem no campo produzindo para o mercado e para sua subsistência, vai perdurar até o esgotamento do estoque de terras disponibilizado pelo Estado para as loteadoras e estas aos compradores individuais, o que vai ocorrer nos anos 1960. O esgotamento do estoque de terras marca, além do encerramento dos negócios imobiliários realizados por intermédio da ação empresarial, o limite do avanço da frente cafeeira na região Norte do Paraná, bem como na sua porção Noroeste.
Considerando que praticamente todos os lotes negociados foram ocupados pelo mesmo tipo de lavoura, não chegou a surpreender quando os preços do café começaram a despencar no encerramento da marcha colonizadora, tendo como causa principal o excesso de oferta do produto no mercado. A queda nos preços vai desencadear uma série de medidas tomadas pelo Estado no sentido de desestimular a atividade cafeeira e convencer os agricultores a optarem por uma nova forma de cultivo, mais segura e mais rentável que o café. Os produtores, no entanto, relutam em abandonar a atividade, alicerçados nos seguintes pontos: eram cafeicultores por tradição e não sabiam lidar com outro produto de mercado além do café; a estrutura da propriedade, voltada ao café, constituída de terreiro, tulha, paiol e outras benfeitorias, havia sido construída com recursos próprios e não teria utilidade em eventual nova opção pelo uso da terra; as lavouras de subsistência garantiam a alimentação da família e ainda viabilizavam algum retorno financeiro com a venda de excedentes, o que significa que mesmo com os prejuízos que sofriam com o café, tinham como se manter na propriedade; o custo da habitação era praticamente nulo, considerando que os produtores moravam em casa própria, portanto não pagavam aluguel e não arcavam com despesas, sequer, com o consumo de energia elétrica, conforto que não existia, na época, no meio rural; a manutenção da família e dos poucos e eventuais trabalhadores contratados tinha como ser extraída do próprio lote; podiam ainda contar com a mão-de-obra familiar não remunerada, economizando assim custos extras com empregados.

A resistência, no entanto, encontra seus limites nos anos 1970: em 1975, fortes geadas destroem completamente o parque cafeeiro regional, estimado em 915 milhões de covas. "As lavouras tinham, enfim, 
sofrido seu golpe de misericórdia e nada mais restava ao produtor, a não ser abandonar toda a infraestrutura que havia formado ao longo dos anos em função do café e começar a construir outra, em torno de um novo produto agrícola" (SERRA, 1986, p. 57). Observa ainda o mesmo autor:

As geadas sempre prejudicaram as lavouras paranaenses, mas nunca na intensidade como acabaram prejudicando em 1975. Foi neste ano que os proprietários rurais resolveram, de vez, substituir o café por outro produto que apresentasse mais segurança em termos de comercialização e menos risco em termos de eventuais instabilidades climáticas. As culturas mecanizadas de soja, trigo e milho, o algodão e as pastagens foram as alternativas que passaram a ter a preferência do agricultor. (SERRA, 1986, p. 57).

\section{AS CARACTERÍSTICAS DO NOVO MODELO}

Em lugar do café, poucos anos depois das geadas de 1975, vão despontar no Noroeste do Paraná as lavouras mecanizadas de soja, trigo e milho, que ocupam preferencialmente as áreas de domínio do solo sobre o basalto e as zonas de contato arenito-basalto, enquanto que os solos sobre o arenito (Formação Caiuá) passam a ser ocupadas pelas lavouras de algodão, em seguida pelas pastagens plantadas tendo em vista a criação de gado de corte como atividade econômica predominante. Define-se desta forma na região uma nova dinâmica do uso do solo, fortemente atrelada ao Complexo Agroindustrial, localizando-se o setor agrícola como base de sustentação econômica de dois setores estruturados no espaço urbano: a montante o de bens para a lavoura, produzindo tratores e outras máquinas, equipamentos, implementos agrícolas, insumos em geral, e a jusante a indústria de transformação, ou agroindústria, esta fortemente atrelada às cooperativas de produtores rurais.

(...) o termo "Complexo Agroindustrial, num sentido estrito estaria referido às fortes articulações de determinada atividade agrícola "para frente" ou a jusante e "para trás" ou a montante, aproximando-se do conceito de cadeia agroindustrial e, portanto, utilizado para designar complexos específicos e determinados. Num sentido lato designaria o processo histórico de desenvolvimento do setor agropecuário, intensificado no final da década de 60 e marcado por um novo padrão de articulação agriculturaindústria, em que a dinâmica das condições de reprodução ampliada da primeira advêm, primordialmente, da segunda. (COSTA, 1992, p. 18).

A nova dinâmica vai viabilizar as condições necessárias para a incorporação de recursos tecnológicos nas práticas agrícolas e que vão, gradativamente, tornando a agricultura menos dependente das condições naturais - o chamado laboratório natural da terra - e também do fator trabalho, e, por outro lado, altamente dependente do fator capital, representado principalmente pela incorporação de máquinas, equipamentos e insumos químicos gerados pelo setor industrial. Em outros termos, as práticas agrícolas se distanciam das características que marcaram a forma tradicional de produzir para se inserirem nas novas formas de produzir segundo as ofertas (máquinas, insumos) e as demandas (matérias primas industriais) dos mercados. Nessa condição, a agricultura se moderniza e se transforma em grande consumidora de máquinas, insumos e outros produtos gerados pela indústria e, ao mesmo tempo, em provedora das matérias primas para indústria de transformação.

Do lado da indústria, criava-se um mercado cativo para as máquinas, os equipamentos e os insumos produzidos. Do lado dos produtores 
rurais, financiavam-se, a prazos relativamente longos e juros negativos, os elementos necessários à transformação na base técnica da produção agropecuária (capital fixo e circulante), bem como as próprias necessidades monetárias criadas pela modernização... (GRAZIANO DA SILVA, 1998, p. 50).

Quando das práticas tradicionais de produção, em que a agricultura era altamente dependente das condições naturais (clima, solo, relevo) e do fator trabalho, as atividades econômicas do setor agrícola se desenvolviam no Noroeste do Paraná com um mínimo de relações com o setor urbano. De maneira geral, a lavoura, atrelada ao complexo cafeeiro regional, internalizava na propriedade agrícola a produção e os meios necessários para obtê-la, só esporadicamente recorrendo ao setor urbano e às funções ali localizadas. Tal quadro se inverte com o novo modelo agrícola, quando a lavoura torna-se muito mais dependente do fator capital. Na nova situação, ela se define como atividade que vende tudo o que produz e compra tudo o que consome, o que significa que de pouco dependente torna-se extremamente dependente das atividades urbanas, incorporadas ao Complexo Agroindustrial.

Estas novas relações entre a agricultura e a indústria, decorrentes da necessidade de transformação da agricultura num modo de produção moderno, começavam a custar a esta última a perda gradativa de sua independência, de tal modo que os fatores de sua modernização se iam tornando, simultânea e contraditoriamente, em fatores de subordinação. Daí por diante, os laços de dependência entre as atividades industriais e as atividades agrícolas foram se tornando mais e mais estreitas. (GUIMARÃES, 1982, p. 95).

No contexto do sistema agrícola do Noroeste do Paraná, as transformações implicaram na incorporação de tecnologia e na consequente dinamização da produ- ção, sinalizando para o moderno, para o novo. $\mathrm{O}$ custo dessa evolução pode ser medido por meio das vantagens auferidas por alguns produtores, transformados em empresários do campo. Estes se capitalizaram, ampliaram seus negócios, se transformaram nos "novos ricos" da região. No entanto, para que a categoria dos proprietários bem sucedidos se firmasse e para que o novo modelo agrícola desse certo, o mercado de terras teve que sofrer uma reviravolta logo após as geadas de 1975, no sentido de anular, de certa forma passar a borracha por cima do modelo fundiário desenhado pelas colonizadoras, baseado nas pequenas e médias propriedades e construir uma nova estrutura que contemplasse propriedades de maior tamanho. A ampliação da área de cultivo passou a ser condição para a incorporação de máquinas agrícolas, tratores, principalmente, e, como consequência, para a modernização e esta só poderia acontecer por meio da incorporação de propriedades menores.

$\mathrm{Na}$ nova fase, marcada pela incorporação fundiária, o número de estabelecimentos agrícolas cai de 85.410 unidades em 1970 para 30.941 em 1996, o que aponta para a eliminação de 54.469 unidades produtivas, enquanto que a área ocupada por esses estabelecimentos se eleva de 1.895.674 hectares em 1970 para 2.208.698 hectares em 1996, o que aponta para a intensificação das áreas de cultivo na região. A redução do número de estabelecimentos e a ampliação da área ocupada, vai se refletir na área média das unidades produtivas, que era de 22,19 hectares em 1970 e passou para 71,38 hectares em 1996. Os estratos de área mais afetados pela concentração foram os de 1 a 10 hectares e de 10 a 20 hectares, justamente os que predominaram no modelo fundiário desenhado pelas colonizadoras na época da ocupação pioneira e do domínio das lavouras de café na região. $O$ estrato de 1 a 10 hectares perdeu 
38.954 estabelecimentos e 223.766 hectares e o estrato de 10 a 20 hectares perdeu 14.418 estabelecimentos e 38.936 hectares no período 1970-1996. Juntos, os dois estratos perderam 53.782 estabelecimentos e 395.536 hectares. As unidades produtivas correspondentes aos estratos menores foram incorporadas aos estratos maiores, seguindo a lógica da modernização da agricultura brasileira. Os estratos maiores que se beneficiaram com a redução dos menores foram os de 100 a 500 hectares, que no mesmo período cresceu $69 \%$ em número e em $63 \%$ em área ocupada e o de mais de 500 hectares, que ampliou em $67 \%$ o número deestabelecimentos e $\mathrm{m} 48 \%$ a extensão da área por eles ocupada (Tabela 1).

Fica evidenciado que a concentração da estrutura fundiária expulsa do campo as categorias dos pequenos e mini produtores rurais, que perdem suas terras em favor das categorias de médios e grandes. Tal marca social do novo modelo agrícola ganha espaço considerando, frise-se, que as novas formas de cultivo, voltadas às lavouras mecanizadas incorporadoras de tecnologias e ainda às pastagens plantadas, passam a justificar a ampliação da área individual decultivo, o que vai se viabilizar com

a incorporação das Tabela 2. Mesorregião Noroeste do Paraná: distribuição do uso da terra (ha) áreas até então ocupadas pelas pequenas unidades produtivas.

Vale observar que o novo modelo agrícola privilegiou as

\begin{tabular}{|l|c|c|c|c|c|}
\hline & $\mathbf{1 9 7 0}$ & $\mathbf{1 9 7 5}$ & $\mathbf{1 9 8 0}$ & $\mathbf{1 9 8 5}$ & $\mathbf{1 9 9 6}$ \\
\hline Lavouras permanentes & 421.993 & 391.135 & 335.493 & 235.580 & 64.402 \\
\hline Lavouras temporárias & 315.399 & 224.425 & 202.513 & 286.439 & 305.933 \\
\hline Áreas de pastagens & 999.537 & 1.430 .917 & 1.582 .322 & 1.594 .475 & 1.663 .748 \\
\hline
\end{tabular}

Fonte: IBGE - Censos Agropecuários de 1970, 1975, 1980, 1985, 1996. sendo que estas, não tendo como se manter economicamente, se tornaram vulneráveis à incorporação.

No Noroeste do Paraná, até os anos 1970, predominaram como formas de uso do solo as lavouras permanentes voltadas ao cultivo do café. Dos anos 1970 em diante as lavouras permanentes perdem importância, e gradativamente vão liberando espaço para as lavouras temporárias e principalmente para as pastagens plantadas, tendo a pecuária de corte como atividade econômica principal. Na prática, as pastagens para a pecuária de corte começam a se destacar na região logo após o início da crise do café, nos anos 1960. Com a crise do café, as pastagens ganham destaque, seguidas pelas lavouras de algodão e mandioca, particularmente no arenito. Em 1996 já se observa a ampliação das áreas de lavouras temporárias, como reflexo da opção pelas lavouras mecanizadas de soja, trigo e milho e principalmente pelo avanço das lavouras de cana-de-açúcar impulsionado pela instalação de usinas de álcool na região (Tabela 2).

Paralelamente à concentração fundiária médias e grandes propriedades em detrimento das pequenas,

e às mudanças no uso do solo, ocorrem

Tabela 1. Noroeste do Paraná: número de estabelecimentos e área ocupada por grupos de área total

\begin{tabular}{|c|c|c|c|c|c|c|}
\hline \multirow{2}{*}{$\begin{array}{c}\text { Estratos } \\
\text { de } \\
\text { Área (ha) }\end{array}$} & \multicolumn{2}{|c|}{$\mathbf{1 9 7 0}$} & \multicolumn{2}{c|}{$\mathbf{1 9 8 0}$} & \multicolumn{2}{c|}{1996} \\
\cline { 2 - 7 } & Est. (n.) & Área (ha) & Est. (n.) & Área (ha) & Est. (n.) & Área (ha) \\
\hline $\mathbf{- 0 1}$ & 757 & 338 & 1.490 & 551 & 374 & 277 \\
\hline $\mathbf{0 1}-\mathbf{1 0}$ & 49.411 & 307.205 & 26.015 & 151.162 & 10.457 & 83.439 \\
\hline $\mathbf{1 0}-\mathbf{2 0}$ & 21.592 & 293.653 & 14.279 & 197.860 & 7.174 & 121.944 \\
\hline $\mathbf{2 0}-\mathbf{5 0}$ & 9.002 & 267.826 & 8.386 & 258.886 & 6.520 & 237.473 \\
\hline $\mathbf{5 0}-\mathbf{1 0 0}$ & 2.006 & 142.278 & 2.732 & 194.599 & 2.541 & 201.625 \\
\hline $\mathbf{1 0 0}-\mathbf{5 0 0}$ & 2.161 & 469.699 & 3.107 & 669.598 & 3.147 & 740.307 \\
\hline$+\mathbf{5 0 0}$ & 481 & 414.675 & 705 & 835.481 & 728 & 863.633 \\
\hline TOTAL & 85.410 & 1.895 .674 & 56.714 & 2.308 .137 & 30.941 & 2248698 \\
\hline
\end{tabular}

Fonte: IBGE - Censos Agropecuários de 1970, 1980, 1996. na região a expulsão e a expropriação de trabalhadores rurais. A mecanização das atividades agrícolas e a prática da utilização em grande escala de insumos químicos, caso dos herbicidas, passam a comprometer o mercado de trabalho no campo e justificar a dispensa em massa de trabalhadores. Como reflexo 
da dinâmica regional o Paraná, que até os anos 1960 se marcou, graças às lavouras de café, como pólo de atração populacional, passou a se destacar como pólo dispersor quando o café entrou em crise e passou a ser substituído pelas lavouras mecanizadas. No Noroeste a população, que até os anos 1970 era predominantemente rural e beirava a casa de um milhão de habitantes, quando o café entrou em crise passa a se urbanizar na tentativa de encontrar nos espaços urbanos o emprego que perdeu no espaço rural; não encontrando, se desloca para outras regiões ou outros Estados. $\mathrm{O}$ resultado desses deslocamentos é de um lado a inversão da população urbana e rural (nos anos 1970, 73,67\% da população moravam no campo e nos anos $200077,27 \%$ passaram a morar nas cidades) e, de outro lado, o próprio esvaziamento populacional: de um contingente de 962.798 habitantes em 1970, o Noroeste caiu para 641.048 habitantes no ano 2000 (Tabela 3). Ou seja: um terço dos moradores deixou a região por conta de dois fatores principais: a diminuição das oportunidades de trabalho no

Tabela 3. Noroeste do Paraná: população total, urbana e rural $1970 / 2000$.

\begin{tabular}{|c|c|c|c|}
\hline PERÍODO & TOTAL & URBANA & RURAL \\
\hline $\mathbf{1 9 7 0}$ & 962.798 & $253.507(26,33 \%)$ & $709.291(73,67 \%)$ \\
\hline $\mathbf{1 9 8 0}$ & 746.472 & $360.966(48,36 \%)$ & $385.506(51,64 \%)$ \\
\hline $\mathbf{1 9 9 1}$ & 655.509 & $441.840(67,40 \%)$ & $213.669(32,60 \%)$ \\
\hline $\mathbf{2 0 0 0}$ & 641.084 & $495.342(77,27 \%)$ & $145.742(22,73 \%)$ \\
\hline
\end{tabular}

Fonte: IPARDES, 2008.

campo, tanto na condição de empregados rurais como na condição de pequenos proprietários fundiários, somando-se a isso a falta de estrutura urbana para absorver os contingentes de expulsos e expropriados do campo.

Em linhas gerais, o novo modelo redesenhou a paisagem agrícola do Noroeste paranaense. No lugar do homem morando no campo e produzindo para o mercado e para a sua subsistência, ficou o campo vazio de gente, mas lotado de pastagens e de lavouras especializadas; no lugar da estrutura fundiária que democratizava o acesso à terra, a concentração tanto na posse quanto no uso da terra agrícola. A nova paisagem que surge depois dos anos 1970, altamente dependente do fator capital e pouco dependente do fator trabalho, é caracterizada a seguir, tomando como referência os quatro municípios da área de estudo: no vale do rio Ivaí, os municípios de Floraí e São Carlos do Ivaí e no vale do rio Piquirí os municípios de Francisco Alves e Alto Piquirí.

\section{A NOVA PAISAGEM NOS VALES DO IVAÍ E DO PIQUIRI}

De maneira geral, os processos de ocupação humana, de colonização e de uso econômico das terras nos vales do rio Ivaí e do rio Piquirí, particularmente nos municípios de Floraí, São Carlos do Ivaí e Francisco Alves, repetem as situações que caracterizaram o Noroeste do Paraná como um todo. A exceção no que se refere à colonização fica por conta do município de Alto Piquirí, onde não foi obedecido o modelo empresarial que marcou a repartição e o acesso à terra nos demais municípios. O território que nos anos 1960 passou a corresponder à extensão geográfica de Alto Piquirí, na prática é produto de uma fase da história agrária paranaense marcada por doações de terra a correligionários políticos do governador do Estado, Sr. Moisés Lupion. Durante os seus dois mandatos como governador do Paraná, de 1946 a 1950 e de 1956 a 1960, o Sr. Lupion se utilizou da prática de pagar apoio político com extensões de terras devolutas, portanto, patrimônio público. Nessa condição, a área que passou a corresponder ao município de Alto Piquirí foi presenteada a 
um apadrinhado político que, entretanto, não usou do "direito" de explorar as terras, mantidas como reserva de valor até o avanço das frentes de ocupação, quando em parte foram ocupadas por posseiros. Para evitar conflitos, governadores que sucederam Lupion passaram a titular as terras em benefício dos posseiros, o que se dá mesmo depois da emancipação de Alto Piquirí como município, na década de 1960. A própria Prefeitura Municipal teve a incumbência de receber e encaminhar ao Estado os requerimentos de terra, depois transformados em escrituras públicas, documento jurídico reconhecendo o direito de propriedade. Para legitimar a posse, o posseiro requerente não pagava pela terra, mas apenas arcava com os custos do registro da propriedade que era feito em Curitiba.

A fase da ocupação pioneira, apesar da particularidade de Alto Piquirí e apesar da distância geográfica (cem quilômetros, aproximadamente) que separa as zonas correspondentes aos vales dos rios Ivaí e do rio Piquirí, foi completada nos anos 1960, em todas as áreas tendo o café como motivação econômica. Em consonância com a situação regional, a crise da cafeicultura, nos mesmos anos 1960, provoca mudanças nas formas de uso do solo, passando a despontar nos quatro municípios, assim como em toda a zona de contato e na mesorregião Noroeste paranaense, num primeiro momento as lavouras de algodão e em seguida as lavouras mecanizadas e as pastagens plantadas ocupando o lugar das lavouras de café. Em termos regionais, como citado anteriormente, as lavouras mecanizadas passam a predominar nos solos de origem basáltica enquanto as pastagens predominam nos solos originários da Formação Arenito Caiuá. Nos chamados solos mistos, onde se localizam as zonas de contato arenito-basalto, o maior domínio das lavouras mecanizadas ou das pastagens plantadas fica na dependência ou do relevo ou de alguma especificidade pedológica local, caso da maior ou menor composição de areia ou de argila, tornando o solo mais propício a uma ou outra forma de cultivo.

Esse quadro de exploração agrícola perdura até os anos 1990, quando em função de estímulos econômicos carreados pelo Programa Nacional do Álcool - PROÁLCOOL, as lavouras de cana despontam na região, ocupando primeiramente as áreas sob o arenito e em seguida avançando sobre as zonas de contato, sendo que atualmente disputam espaço com as lavouras mecanizadas de soja, trigo e milho nos solos de origem basáltica. Em algumas situações, independente do tipo ou da formação do solo, as lavouras de cana dominam na maior parte do espaço agrícola, contribuindo para isso a localização de usinas de açúcar e álcool. A proximidade ou o distanciamento do município em relação às instalações da usina interfere na maior ou menor territorialização dos canaviais, considerando que o maior distanciamento onera os custos de transporte e da produção industrial e inviabiliza a cultura enquanto atividade econômica. Territorialização, nesse sentido, corresponde à conquista, apropriação/ dominação de espaços geográficos para determinadas formas de produção, que se dá, segundo Castells (1999), em função da excepcional capacidade da economia capitalista de ajustar, em escala planetária, a interdependência entre as condições de tempo e espaço no processo global de produção de mercadorias. A propósito, territorialização deriva do termo território que tem a seguinte origem, de acordo com Haesbaert (2004): 
Etimologicamente, a palavra território, territorium em latim, é derivada diretamente do vocábulo latino terra e era utilizado pelo sistema jurídico romano dentro do chamado jus terrendi (...) como pedaço de terra apropriado dentro dos limites de uma determinada jurisdição políticoadministrativa. (HAESBAERT, 2004, p. 43).

A territorialização das lavouras de cana depende da localização da indústria de transformação, sendo que a distância máxima considerada entre a lavoura e a indústria não pode exceder a 50 quilômetros. Passando desse limite, o custo da quilometragem extra rodada pelos caminhões coletores de cana acaba sendo pago pelo dono da terra pela via do menor valor do arrendamento. Em linhas gerais, dois fatores são primordiais, ou determinantes, para o maior ou menor avanço das lavouras de cana no Noroeste do Paraná: a localização de usinas de açúcar e álcool numa distância não superior a 50 quilômetros e o comportamento do mercado, principalmente de álcool combustível. Usina próxima contribui para a definição do perfil agrícola em alguns municípios e preços do açúcar e álcool em alta justificam aumentos na área plantada mesmo em locais considerados pouco apropriados para a lavoura, como aqueles onde o relevo apresenta vertentes com declividades mais fortes, dificultando a movimentação de máquinas. Nos vales dos rios Ivaí e Piquirí, considerando apenas as áreas de pesquisa, três usinas absorvem a produção e controlam todo o mercado de cana: a Santa Terezinha, sediada em Maringá, mas com área de atuação em praticamente todo o vale do Ivaí; a COOPCANA - Cooperativa dos Produtores de Cana, instalada no município de São Carlos do Ivaí e que também atua no vale do Ivaí e a SABARÁLCOOL, que atua no vale do Piquirí por intermédio da usina instalada no município de Perobal. Com a participação dessas usinas, o comportamento das lavouras de cana nos municípios de Alto Piquirí, Francisco Alves, Floraí e São Carlos do Ivaí apresentase da seguinte forma (Tabela 4):

Os dados do ano 2008 da Secretaria de Agricultura e Abastecimento do Estado

Tabela 4. Lavouras de cana nos municípios de Alto Piquirí, Floraí, rancisco Alves e São Carlos do Ivaí.

\begin{tabular}{|l|c|c|c|}
\hline \multicolumn{1}{|c|}{ MUNICÍPIO } & ÁREA COLHIDA (ha) & PRODUÇÃO (ton.) & $\begin{array}{c}\text { RENDIMENTO } \\
\text { (kg/ha) }\end{array}$ \\
\hline Alto Piquirí & 3.612 & 272.865 & 75.544 \\
\hline Floraí & 985 & 71.372 & 72.459 \\
\hline Francisco Alves & & & \\
\hline São Carlos do Ivaí & 7.646 & 711.361 & 93.037 \\
\hline
\end{tabular}

Fonte: SEAB/DERAL, 2008.

do Paraná, por intermédio de seu Departamento de Economia Rural, relativos aos municípios escolhidos para o desenvolvimento da pesquisa sinalizam, pelo menos, para duas situações: no município de Francisco Alves as lavouras de cana não concorrem com outras formas de cultivo, o que pode ser justificado pela distância da usina (a mais próxima está há mais de 50 quilômetros, no município de Perobal, também localizado no vale do rio Piquirí), o que compromete os lucros da produção considerando os custos do transporte da matéria prima; no município de São Carlos do Ivaí, a produtividade média local supera a produtividade média do Estado, o que pode ser explicado pelas condições naturais do solo e pelos níveis de tecnologia adotada. A consistência de tais situações se comprova quando os dados da SEAB/ DERAL são cruzados com os dados do IBGE, que, da mesma forma, evidenciam a ausência das lavouras de cana em Francisco Alves e a forte presença dessas lavouras em São Carlos do Ivaí (Tabela 5). 
Em São Carlos do Ivaí, as lavouras de cana, que foram introduzidas em meados dos anos 1980, mesma época da instalação

Tabela 5. Principais produtos cultivados: municípios de Alto Piquirí, Francisco Alves, Floraí e São Carlos do Ivaí - 1985/2005.

\begin{tabular}{|c|c|c|c|c|c|c|c|c|}
\hline \multicolumn{9}{|c|}{ Alto Piquirí } \\
\hline \multirow[b]{2}{*}{$\begin{array}{l}\text { Safra } \\
\text { (ano) }\end{array}$} & \multicolumn{2}{|c|}{ SOJA } & \multicolumn{2}{|c|}{ TRIGO } & \multicolumn{2}{|c|}{ MILHO } & \multicolumn{2}{|c|}{ CANA } \\
\hline & $\begin{array}{l}\text { Quant. } \\
\text { (ton.) }\end{array}$ & $\begin{array}{c}\text { Área } \\
\text { (ha) }\end{array}$ & $\begin{array}{l}\text { Quant. } \\
\text { (ton.) }\end{array}$ & $\begin{array}{c}\text { Área } \\
\text { (ha) }\end{array}$ & $\begin{array}{l}\text { Quant. } \\
\text { (ton.) }\end{array}$ & $\begin{array}{c}\text { Área } \\
\text { (ha) }\end{array}$ & $\begin{array}{c}\text { Quant. } \\
\text { (ton.) }\end{array}$ & $\begin{array}{c}\text { Área } \\
\text { (ha) }\end{array}$ \\
\hline $1985^{1}$ & 10.535 & 5.000 & 10.535 & 5.000 & 13.511 & 4.600 & 1.500 & 30 \\
\hline $1996^{1}$ & 4.380 & 1.635 & 1.680 & 1.200 & 3.280 & 800 & 192.502 & 2.560 \\
\hline $2000^{2}$ & 18.125 & 7.250 & 2.836 & 1.973 & 4.365 & 3.760 & 187.447 & 3.605 \\
\hline $2005^{2}$ & 37.950 & 16.500 & 2.300 & 1.000 & 3.500 & 1.250 & 285.778 & 3.665 \\
\hline \multicolumn{9}{|c|}{ Francisco Alves } \\
\hline \multirow[b]{2}{*}{$\begin{array}{l}\text { Safra } \\
\text { (ano) }\end{array}$} & \multicolumn{2}{|c|}{ SOJA } & \multicolumn{2}{|c|}{ TRIGO } & \multicolumn{2}{|c|}{ MILHO } & \multicolumn{2}{|c|}{ CANA } \\
\hline & $\begin{array}{l}\text { Quant. } \\
\text { (ton.) }\end{array}$ & $\begin{array}{l}\text { Área } \\
\text { (ha) }\end{array}$ & $\begin{array}{l}\text { Quant. } \\
\text { (ton.) }\end{array}$ & $\begin{array}{c}\text { Área } \\
\text { (ha) }\end{array}$ & $\begin{array}{l}\text { Quant. } \\
\text { (ton.) }\end{array}$ & $\begin{array}{c}\text { Área } \\
\text { (ha) }\end{array}$ & $\begin{array}{l}\text { Quant. } \\
\text { (ton.) }\end{array}$ & $\begin{array}{c}\begin{array}{c}\text { Área } \\
\text { (ha) }\end{array} \\
\end{array}$ \\
\hline $1985^{1}$ & 2.418 & 1.300 & 2.107 & 1.000 & 3.492 & 1.500 & 3.500 & 70 \\
\hline \multicolumn{9}{|c|}{ Floraí } \\
\hline \multirow[b]{2}{*}{$\begin{array}{l}\text { Safra } \\
\text { (ano) }\end{array}$} & \multicolumn{2}{|c|}{ SOJA } & \multicolumn{2}{|c|}{ TRIGO } & \multicolumn{2}{|c|}{ MILHO } & \multicolumn{2}{|c|}{ CANA } \\
\hline & $\begin{array}{l}\text { Quant. } \\
\text { (ton.) }\end{array}$ & $\begin{array}{c}\text { Área } \\
\text { (ha) }\end{array}$ & $\begin{array}{l}\text { Quant. } \\
\text { (ton.) }\end{array}$ & $\begin{array}{c}\text { Área } \\
\text { (ha) }\end{array}$ & $\begin{array}{l}\text { Quant. } \\
\text { (ton.) }\end{array}$ & $\begin{array}{c}\text { Área } \\
\text { (ha) }\end{array}$ & $\begin{array}{c}\text { Quant. } \\
\text { (ton.) }\end{array}$ & $\begin{array}{c}\text { Área } \\
\text { (ha) }\end{array}$ \\
\hline $1985^{1}$ & 17.367 & 7.644 & 8.938 & 4.083 & 3.951 & 1.944 & 11.299 & 114 \\
\hline $1996^{1}$ & 20.250 & 7.500 & 3.380 & 2.600 & 15.820 & 6.400 & 93.740 & 1001 \\
\hline $2000^{2}$ & 22.176 & 10.080 & 560 & 922 & 11.010 & 6.353 & 29.072 & 430 \\
\hline $2005^{2}$ & 27.950 & 13.000 & 740 & 400 & 27.845 & 6.600 & 105.000 & 1.050 \\
\hline \multicolumn{9}{|c|}{ São Carlos do Ivaí } \\
\hline \multirow[b]{2}{*}{$\begin{array}{l}\text { Safra } \\
\text { (ano) }\end{array}$} & \multicolumn{2}{|c|}{ SOJA } & \multicolumn{2}{|c|}{\begin{tabular}{|c|} 
TRIGO \\
\end{tabular}} & \multicolumn{2}{|c|}{ MILHO } & \multicolumn{2}{|c|}{ CANA } \\
\hline & $\begin{array}{l}\text { Quant. } \\
\text { (ton.) }\end{array}$ & $\begin{array}{c}\text { Área } \\
\text { (ha) }\end{array}$ & $\begin{array}{l}\text { Quant. } \\
\text { (ton.) }\end{array}$ & $\begin{array}{c}\text { Área } \\
\text { (ha) }\end{array}$ & $\begin{array}{l}\text { Quant. } \\
\text { (ton.) }\end{array}$ & $\begin{array}{c}\text { Área } \\
\text { (ha) }\end{array}$ & $\begin{array}{l}\text { Quant. } \\
\text { (ton.) }\end{array}$ & $\begin{array}{c}\text { Área } \\
\text { (ha) }\end{array}$ \\
\hline $1985^{1}$ & 1.378 & 1.029 & 2.382 & 1.200 & 1.180 & 600 & 72.000 & 900 \\
\hline $1996^{1}$ & 1 & 5 & 250 & 250 & 1.540 & 600 & 530.421 & 5.190 \\
\hline $2000^{2}$ & 22 & 12 & 132 & 120 & 927 & 1.592 & 488.646 & 6.236 \\
\hline $2005^{2}$ & 30 & 30 & 8 & 5 & 6.560 & 2.040 & 650.126 & 8.265 \\
\hline
\end{tabular}

Fontes: 1 IBGE - Censos Agropecuários, 2 IBGE - Produção Agrícola Municipal.

da usina COOPCANA, superam em área cultivada e em produção colhida todas as outras lavouras, no seu conjunto. $\mathrm{O}$ avanço da cana ocorre em detrimento das demais lavouras temporárias, mas principalmente em detrimento das lavouras de soja, que a partir dos anos 1980 passam a perder espaço para a nova cultura, a ponto de no final dos anos 1990 e início dos anos 2000 não ter, praticamente, nenhuma importância econômica, conforme evidenciam os dados da Tabela 5. A nova dinâmica do uso do solo cria uma nova paisagem nesses setores dos vales dos rios Piquirí e Ivaí em função do avanço das lavouras de cana e de sua concorrência, num primeiro momento com as pastagens predominantes nas zonas de domínio do arenito e mais recentemente com as lavouras de soja nas zonas de contato arenito-basalto e nas zonas de solos basálticos. As atividades econômicas, envolvendo tipos, formas e características do que é cultivado e explorado comercialmente, no caso as lavouras de cana, é que vão caracterizar a nova paisagem construída.

A partir dos dados censitários e dos dados produzidos pelos órgãos de pesquisa do governo do Paraná, particularmente da Secretaria de Agricultura, procurouse ouvir pequenos agricultores, categoria mais afetada pelo avanço das lavouras de cana, bem como técnicos vinculados a órgãos de apoio aos produtores rurais, caso da EMATER, nas duas áreas tomadas como referência no presente estudo, ou seja: os dois municípios do vale do rio Ivaí e os dois municípios do vale do Piquirí.

No vale do rio Ivaí, segundo informações do técnico da EMATER, escritório de Floraí, geógrafo José Antonio de Andrade, "a cana avançou muito nos últimos dois anos e meio. E avançou sobre as áreas de basalto, depois de dominar as áreas de arenito", destacando que em Floraí "a cana saiu de 1.200 a 1.300 hectares e foi para praticamente quatro mil hectares". $\mathrm{O}$ domínio territorial dos canaviais tem, por parte do técnico José Carlos, as seguintes justificativas:

- AGRESSIVIDADE DAS USINAS. Até o ano 2008, as usinas se empenharam ao máximo para aumentar a produção de ál- 
cool porque o mercado, particularmente o externo, estava favorável por conta do alto custo do barril de petróleo, que chegou a ser cotado acima de 140 dólares, e das discussões para o aproveitamento de fontes alternativas de energia (biocombustíveis). Para aumentar a produção, elevaram os preços que pagavam pelos arrendamentos de terra; ganhando mais, os proprietários rurais se convenceram de que, entre explorar diretamente a terra, assumindo todos os riscos da atividade, e arrendar a propriedade para a usina explorar, era melhor negócio arrendar.

-QUEDA NOS PREÇOS DA SOJA. Na mesma época em que os preços do álcool disparavam no mercado externo, os preços da soja entravam em declínio nos mesmos mercados por conta da superprodução mundial e da queda nas cotações do dólar. Ganhando menos com a soja, os proprietários rurais se sentiram estimulados a entregar suas terras para as usinas. Assim, passaram a economizar os custos da produção, que no processo de arrendamento ficam por conta da usina e se livraram dos riscos de eventuais frustrações de safras e de eventuais prejuízos que poderiam ser gerados pelos baixos preços da soja pagos pelos compradores externos.

- IDADE DO AGRICULTOR. Os proprietários rurais no vale do Ivaí, de maneira geral, estão com idade avançada, acima de 60 anos, já cansados da atividade agrícola e com dificuldades para passar o comando do negócio para os filhos porque estes, também de maneira geral, não se interessam pelo negócio dos pais e relutam em assumir o comando das propriedades. Assim, cria-se um dilema para o agricultor: tem dificuldade em continuar, não consegue delegar poderes para nova geração e não está disposto a se desfazer da propriedade. A solução acaba sendo o arrendamento da propriedade para as usinas e a transferência da moradia para o espaço urbano.

Afirma Andrade que esse quadro foi favorável ao avanço das lavouras de cana, exploradas diretamente pelas usinas, nos últimos anos, situação que se estabiliza em 2008 para sofrer ligeira reversão a partir daí. "O avanço estabilizou porque as commodities agrícolas, soja e milho principalmente, passaram a ter preços mais elevados em relação à cana", justificou, acrescentando que, de um lado a soja e o milho passaram a ter cotações mais elevadas no mercado de commodities agrícolas e, de outro lado, as usinas haviam atingido sua capacidade máxima de produção de álcool. "A capacidade das usinas começa a chegar ao limite, o que inibe novos arrendamentos e gera queda nos preços quando das renovações dos contratos".

Segundo o técnico da EMATER, as usinas preferem arrendar a comprar terras para o plantio de cana, citando que o arrendamento é feito tendo por base toneladas de cana colhida. Ou seja: os contratos são celebrados usando como aluguel da terra toneladas de cana como se fosse moeda corrente. A própria usina absorve a produção destinada ao pagamento do arrendamento, momento em que o aluguel da terra é convertido em dinheiro. Dependendo da usina com a qual mantém contrato, o proprietário rural do Vale do Ivaí recebe entre 35 a 50 toneladas de cana por alqueire, sendo que a variação leva em conta o tipo de solo e a distância entre a propriedade e a usina.

Afirma ainda o técnico José Antonio de Andrade que normalmente "os arrendamentos são feitos por cinco anos, sendo que cada corte é feito a cada 13, 15 meses em média, exceção do primeiro corte que é feito aos 18 meses após a correção e o e preparo do solo. A variação depende muito do tipo de solo e da variedade da cana plantada. É prática da usina plantar diferentes variedades para que o ciclo da 
colheita ocorra em períodos diferentes, facilitando a programação do corte", acrescentando que "a terra só fica ociosa, pelo menos sem o corte da cana, entre os meses de dezembro e abril, período da entressafra em que as usinas aproveitam para fazer a manutenção de seus equipamentos industriais e para efetuar os tratos culturais necessários aos novos plantios; durante os oito ou nove meses restantes do ano, que vão de abril ou início de maio até novembro ou início de dezembro, o corte de cana é rotina na região Noroeste".

Para o proprietário, o arrendamento não deixa de ser bom negócio, considerando que todos os riscos e os custos da produção correm por conta da usina. Para a usina, no entanto, o negócio é bem melhor: mesmo cobrindo todos os custos e assumindo todos os riscos, o lucro do usineiro é bem maior do que a fatia deixada com o dono da terra, considerando que no vale do Ivaí, de acordo com cálculos da EMATER, a produtividade da cana gira entre 280 e 300 toneladas por alqueire. $\mathrm{Ou}$ seja: a usina paga entre 35 e 50 toneladas para produzir, na mesma área, entre $280 \mathrm{e}$ 300 toneladas. Deve ser considerado, por outro lado, que quando arrenda a terra a usina executa um bom trato cultural nos dois primeiros anos, corrigindo o solo, fazendo a calagem e a adubação, enfim, investindo na terra visando a garantia de um bom retorno. No terceiro ano do contrato, a manutenção é suficiente para a garantia de bons índices de produção; no quarto ano reinicia os tratos culturais, mas em menor intensidade, comparados aos dois primeiros anos; no quinto e último ano do contrato, duas situações podem ocorrer: como o solo evidencia esgotamento, a usina volta a fazer investimentos pesados para reiniciar o ciclo de exploração da terra, no caso do proprietário manifestar interesse em renovar o contrato ou a usina retira a produção e deixa de investir na recuperação da terra, caso o proprietário não se interesse em continuar o arrendamento. Detalhe: neste caso o proprietário, ao ter a terra de volta, acaba assumindo os custos da recuperação, o que pode consumir todo o capital acumulado durante o período em que se desvinculou da exploração direta da terra. Além dos custos da recuperação do solo, o proprietário tem que investir na reconstrução das benfeitorias necessárias para a nova forma de exploração da terra, considerando que imediatamente após a efetivação do contrato de arrendamento, a primeira providência da usina é livrar a área de tudo o que pode atrapalhar o pleno e total domínio do canavial, o que significa eliminar casas, galpões, pomares, cercas, etc..

O técnico Cláudio Gilberto Kriki, responsável pelo escritório da EMATER em São Carlos do Ivaí, afirmou que em função das usinas de açúcar e álcool, os arrendamentos de terra estão mudando radicalmente a paisagem no vale do Ivaí. "Aqui em São Carlos, pequeno produtor morando e produzindo no sítio está acabando" porque as usinas "arrendam as grandes, mas também as pequenas propriedades" e o resultado é que "hoje temos em São Carlos mais de $90 \%$ de taxa de urbanização". Normalmente, as usinas preferem as grandes e médias propriedades para arrendar, mas as pequenas acabam também sendo absorvidas em duas situações: quando são vizinhas de uma propriedade maior, compensando a incorporação e quando estão concentradas e todos os proprietários optam pelos contratos que têm o prazo de cinco anos como vigência mínima.

Ao passar a terra para a usina, o proprietário rompe seu vínculo com a atividade agrícola, perde sua identidade como produtor rural e se transfere para o espaço urbano. Ato contínuo, afirma o sr. Gilberto Kriki, a propriedade é transformada num mar de cana "e o proprietário não consegue mais saber onde estava o carreador, nem onde estavam as casas, demolidas 
para cana avançar. Algumas vezes, ele nem consegue dizer onde estava a própria propriedade, misturada entre outras tantas que, da mesma forma, foram arrendadas e cobertas pelos canaviais".

Mas há produtor que resiste na terra, apesar de admitir que "o pequeno produtor vai desaparecer, podem ter certeza disso". É o sr. Antonio Jerônimo Debrino, dono de dois alqueires em Floraí, onde tem um barracão de criação de frangos que entrega para um abatedouro de Maringá. Afirma o sr. Antonio que "agricultura, hoje em dia, só dá dinheiro para o grande". Referindo-se à produção de frangos, afirmou que "o grande ganha alguns centavos por cabeça e fica rico enquanto o pequeno passa fome". Como desabafo, afirmou: "o problema do pequeno está lá em Brasília: eles dão com uma mão e tiram com a outra", reclamando da burocracia para liberar financiamento para a pequena produção. "Outro problema que o pequeno enfrenta é não ter como estocar a produção. Colheu, tem que entregar, não importa o preço. $\mathrm{O}$ grande tem armazém, pode esperar pelo melhor preço. $\mathrm{O}$ pequeno fica nas mãos dos outros" - afirmou.

Ao contrário do sr. Antonio Jerônimo Debrino, de Floraí, em Alto Piquirí foi localizado um pequeno proprietário rural que não reclama da vida que leva na roça. Em um alqueire de terra, "vivo como gente rica" - admite o sr. José Emídio do Nascimento, mais conhecido como Zé Gavião, proprietário de uma chácara que ostenta o nome Pouso do Gavião. O segredo do sucesso é que esse pequeno proprietário vive "na terra", mas não "da terra". Da terra tira apenas a complementação da renda, criando cabras, bodes de raça e mantendo algumas vacas leiteiras. O que mantém, mesmo, o padrão de vida de Zé Gavião são as atividades fora da pequena propriedade. Em Alto Piquirí é locutor de rádio e narrador de rodeios, atividades que lhe abrem espaço para um negócio altamente lucrativo: a compra e engorda de bezerros.

A situação tranquila do sr. José Emídio, no entanto, não traduz o padrão de vida dos pequenos proprietários rurais da região do vale do Piquirí. O sr. Alaércio Francisco da Silva, gerente municipal da EMATER em Alto Piquirí explica que "o pequeno produtor hoje vive em dificuldades. Quando é produtor familiar ainda consegue ter uma renda, embora suficiente apenas para a sustentação da família na propriedade, porque não paga, ou paga pouco pela mão de obra que utiliza, mas quando tem que pagar pela mão-de-obra, ou paga pela terra arrendada, aí a dificuldade é maior". As dificuldades atingem mais os pequenos, mas não estão distantes dos médios e grandes proprietários no vale do Piquirí, situação que facilita o avanço das lavouras de cana por conta dos arrendamentos de terra. Afirma o sr. Alaércio que "hoje deve existir uns doze mil alqueires plantados de cana no vale do Piquirí, sendo três mil só em Alto Piquirí. Como a pecuária, que era forte na região, passou por uma crise bastante intensa e com a implantação da usina de açúcar e álcool no município de Perobal, esses produtores começaram a arrendar suas propriedades de pastagens, até porque eram solos degradados, estavam em estágio bem avançado de depauperação e aí começaram a arrendar porque a usina fazia todo o trabalho de recuperação desses solos". Explica que a crise dos pecuaristas que predominavam no arenito, associada ao empobrecimento desse tipo de solo justifica o motivo da cana, no vale do Piquirí, ter avançado muito nas antigas áreas de pastagem. "Temos propriedades de 300, 500 alqueires onde se desenvolvia uma pecuária moderna, com tecnologia bem aplicada, arrendadas para a cana".

Da mesma forma como ocorre no vale do Ivaí, no vale do Piquirí o envelhecimento do produtor rural acaba também servindo de justificativa para o arrendamento 
da propriedade. Afirma o sr. Alaércio Francisco da Silva que "as novas gerações nem sempre estão dispostas a continuar no campo. No caso do falecimento do patriarca, o que ocorre é a venda do lote para divisão do dinheiro, situação mais comum quando a propriedade é pequena, mas que também atinge as propriedades maiores". Como particularidade, citou que "diante da situação em que o pai tem a propriedade e mora na cidade, que é o que mais acontece por aqui, afirmo que $90 \%$ dos herdeiros não querem saber da atividade rural e colocam a propriedade à venda". Para ilustrar, citou um caso pessoal: "Tenho 13 alqueires de terra e um filho com 13 anos de idade. Quando o convido para ir ao sítio, ele não aceita; esses dias ele me falou assim: olha pai, você pode trabalhar no sítio, fazer o que quiser lá, mas o dia que você morrer a primeira coisa que vou fazer é colocar o sítio à venda".

\section{CONSIDERAÇÕES FINAIS}

A mesorregião Noroeste do Paraná teve todo seu processo de colonização completado nos anos 1960, tendo as lavouras de café como base econômica e as lavouras de subsistência viabilizando a fixação do homem no campo. Lavouras de consumo e lavouras de mercado, uma completando a outra, foram os pontos de sustentação do modelo colonizador, alicerçado na pequena e na média propriedade rural.

Tal modelo, impulsionado pela colonização empresarial privada, garantiu a ocupação rápida e dinâmica de praticamente todo o espaço regional, tendo sempre as lavouras de café como sustentação econômica e incentivadora dos negócios imobiliários. O ponto de equilíbrio - pequena e média propriedades de um lado, lavouras de café de outro - entra em crise, no entanto, logo que se completa a colonização, dando condições para que outro modelo se viabilizasse, não só no Noroeste mas em todo o Norte do Paraná. A crise do café, que gerou a crise do modelo de ocupação, desencadeia uma série de modificações na paisagem, afetando os sistemas econômicos voltados ao uso da terra agrícola e o próprio comportamento social do produtor, proprietário ou não.

No contexto das modificações geradas na paisagem rural, o homem abandona o campo enquanto local de moradia, toda a estrutura do lote criada em função do café desaparece, e olugar do café é ocupado, nos solos derivados do basalto em sua maior parte pelas lavouras mecanizadas (soja, trigo e milho, principalmente) e nos solos originados do arenito da Formação Caiuá pelas lavouras de algodão e mandioca e pelas pastagens tendo em vista o desenvolvimento da pecuária de corte enquanto atividade econômica predominante. Essa paisagem vai sofrer novas e profundas alterações na virada do milênio, com a entrada das lavouras de cana-de-açúcar, que num primeiro momento ocupam o lugar das pastagens no arenito e logo em seguida passam a disputar espaço com as lavouras mecanizadas de soja, trigo e milho, nos solos basálticos. Nas zonas de contato arenito-basalto, objetos do presente estudo, ora predominam as lavouras de cana, ora as lavouras de soja, sendo que o avanço de uma ou outra forma de uso do solo passa a depender do comportamento do mercado de commodities agrícolas. Assim, quando a soja obtém os melhores preços, seu cultivo avança e quando a cana é que tem os preços em alta, os proprietários preferem arrendar suas terras para as usinas para que estas desenvolvam os plantios de cana sob a forma de arrendamento.

A nova dinâmica do uso do solo tem seus pontos positivos para as médias e grandes áreas de cultivo, mas dificulta a manutenção da pequena propriedade rural, justamente a base do modelo de colonização regional, em que os pequenos 
estratos de área se viabilizam economicamente com as lavouras de café. Com poucas alternativas de sobrevivência, as pequenas unidades desaparecem gradativamente, tendo suas áreas incorporadas às propriedades maiores. $\mathrm{O}$ quadro de concentração fundiária, que se manifesta com a entrada das lavouras mecanizadas de soja, trigo e milho e com as pastagens plantadas, vai se agravar com a chegada da cana, tendo como causas principais a falta de opção econômica para as pequenas unidades produtivas e o apetite por terra por parte das usinas de açúcar e álcool. Ao atingirem o limite máximo de produtividade nas terras já conquistadas, as usinas, para aumentarem a produção de açúcar e álcool não têm alternativas, a não ser ampliar as áreas de cultivo, o que se dá pela via da incorporação de novas áreas, boa parte ocupada pelas pequenas propriedades.

A concentração fundiária, impulsionada pela crescente necessidade das usinas de ampliarem suas áreas de cultivo, ganha um novo componente, na condição de aliado, na medida em que os proprietários, principalmente das pequenas unidades, atingem idade avançada sem ter, na nova geração, quem se interesse em dar continuidade à exploração direta da terra. A falta de interesse dos filhos em assumir o negócio dos pais vai se constituir em um novo fator a favorecer a concentração fundiária e, ao mesmo tempo, a destruir a identidade do trabalhador rural. Sem condições de continuar explorando seu espaço de produção, o proprietário recorre aos arrendamentos e passa a viver, não mais dos frutos da terra como sempre fez, mas do aluguel pago por ela pelas usinas.

Em linhas gerais, são pontos que caracterizam a nova paisagem regional e que no presente trabalho são analisados, tendo como referência quatro municípios: dois no vale do rio Ivaí - Floraí e São Carlos do Ivaí e dois no vale do rio Piquirí - Francisco Alves e Alto Piquirí.

\section{REFERÊNCIAS}

CASTELLS, Manuel. A sociedade em rede. A era da informação: economia, sociedade e cultura. 3.ed. Rio de Janeiro: Paz e Terra, 1999.

COSTA, Vera Henriques de Miranda. A modernização da agricultura no contexto da constituição do Complexo Agroindustrial no Brasil. In: ENCONTRO NACIONAL DE GEOGRAFIA AGRÁRIA, 11., 1992. Maringá, Anais... Maringá: Universidade Estadual de Maringá, 1992.

CTNP, Companhia de Terras Norte do Paraná. Colonização e Desenvolvimento do Norte do Paraná. São Paulo, s/edit., 1975 (edição comemorativa dos 50 anos da CTNP).

GOVERNO DO PARANÁ. Secretaria de Estado da Agricultura e do Abastecimento. Departamento de Economia Rural. Área colhida e produção obtida de cana-de-açúcar, por município. Curitiba:SEAB/ DERAL, 2008.

GRAZIANO DA SILVA, José. A nova dinâmica da agricultura brasileira. 2. ed. Campinas: Unicamp, 1998.

GUIMARÃES, Alberto Passos. A crise agrária. 3. ed. Rio de Janeiro: Paz e Terra, 1982.

HAESBAERT, Rogério. O mito da desterritorialização: do fim dos territórios à multiterritorialidade. Rio de Janeiro: Bertrand, 2004.

IBGE - Instituto Brasileiro de Geografia e Estatística. Censos agropecuários: 1970, 1975, 1980, 1985, 1996.

. Produção agrícola municipal: 2000, 2005.

SERRA, Elpídio. Contribuição ao estudo do cooperativismo na agricultura do Paraná: o caso da Cooperativa de Cafeicultores e Agropecuaristas de Maringá. Dissertação (Mestrado em Organização do Espaço) - Instituo de Geociências e Ciências Exatas, UNERSP, Rio Claro, 1986.

Recebido em 01/08/2009

Aceito em 26/10/2009 